\title{
MINECRAFT E INOVAÇÃO: ESTUDO DO DESENVOLVIMENTO DE UM MINDSET CRIATIVO EM OFICINAS COM TEMÁTICAS VINDAS DOS JOGOS
}

Michel Souza

Universidade Federal de Minas Gerais/Universidade do Estado de Minas Gerais

contato@michelsouza.com.br

Pedro Henrique Mendonça Marques

Universidade do Estado de Minas Gerais

pedrohmm16@gmail.com

Resumo: $O$ universo em que a juventude encontra-se imersa está em constante e cada vez mais acelerada transformação, a relação, visão e desenvolvimento das crianças com o mundo que nos cerca também encontra-se em constante movimento. O universo infantil atual é, mais do que nunca, permeado pelo mundo virtual. As diferentes mídias se tornam cada vez mais parte integrante de suas vidas, sejam os filmes, jogos, músicas ou o que for. $O$ acesso imediato e quase irrestrito tornou-se facilitado. Dentro do universo dos jogos, em 2011 a empresa desenvolvedora sueca Mojang lançou o Minecraft A liberdade de construção e manipulação do mundo virtual e seus sistemas dentro do jogo apresenta um grande potencial para estudo do desenvolvimento de uma cultura de inovação na infância e como os benefícios do jogo podem ser canalizados e transportados para os desafios lógicos do mundo real. A liberdade de construção e manipulação do mundo virtual e seus sistemas apresenta um grande potencial para estudo do desenvolvimento de uma cultura de inovação na infância e como os benefícios do jogo podem ser canalizados e transportados para os desafios lógicos do mundo real. $\mathrm{O}$ artigo em questão visa analisar o processo de desenvolvimento da criatividade e da inovação na infância através do uso do universo do Minecraft e deve condensar resultados obtidos através de experimentação em oficinas específicas desenvolvidas com crianças. Alguns pontos específicos de atenção são as relações entre o jogo e o desenvolvimento de uma mentalidade projetual voltada à resolução de problemas, compreender como as crianças lidam com a inovação diante de desafios, experimentar diversas formas de aplicação de conceitos do jogo com finalidade de exercitar a busca por soluções de problemas reais e fomentar uma consciência coletiva para que soluções sejam alcançadas de forma mais universal e assertiva.

Palavras-chave: Inovação, criatividade, educação, infância 